\title{
CHEMOPREVENTIVE ACTIVITY OF METHANOL EXTRACT OF MELASTOMA MALABATHRICUM LEAVES IN DMBA-INDUCED MOUSE SKIN CARCINOGENESIS
}

\author{
Ooi Kah Kooi ${ }^{1}$, Cheah Yee Ling ${ }^{1}$, Roihanah Rodzi $^{1}$, Fezah Othman ${ }^{1}$, Norhafizah Mohtarrudin ${ }^{3}$, Zarizal \\ Suhaili ${ }^{4}$, and Zainul Amiruddin Zakaria ${ }^{1,2, *}$
}

${ }^{1}$ Department of Biomedical Science, Faculty of Medicine and Health Sciences, Universiti Putra Malaysia, 43400

UPM Serdang, Selangor, Malaysia. ${ }^{2}$ Halal Product Research Institute, Universiti Putra Malaysia, 43400 UPM

Serdang, Selangor, Malaysia. ${ }^{3}$ Department of Pathology, Faculty of Medicine and Health Sciences, Universiti Putra Malaysia, 43400 UPM Serdang, Selangor, Malaysia. ${ }^{4}$ Faculty of Agriculture and Biotechnology, Universiti Sultan Zainal Abidin, Kampus Kota, Jalan Sultan Mahmud, 20400 KualaTerengganu, Malaysia.

*E-mail: dr_zaz@yahoo.com

\begin{abstract}
Background: Melastoma malabathricum L. Smith (family Melastomaceae) is a shrub that has been used by the Malay practitioners of traditional medicine to treat various types of ailments. The present study aimed to determine the chemopreventive activity of methanol extract of M. malabathricum leaves (MEMM) using the standard 7,12-dimethylbenz( $\alpha$ )anthracene (DMBA)/croton oil-induced mouse skin carcinogenesis model.

Materials and Methods: In the initiation phase, the mice received a single dose of $100 \mu 1 / 100 \mu \mathrm{g}$ DMBA (group I-V) or $100 \mu \mathrm{l}$ acetone (group VI) topically on the dorsal shaved skin area followed by the promotion phase involving treatment with the respective test solutions $(100 \mu \mathrm{lof}$ acetone, $10 \mathrm{mg} / \mathrm{kg}$ curcumin or MEMM $(30,100$ and $300 \mathrm{mg} / \mathrm{kg})$ ) for $30 \mathrm{~min}$ followed by the topical application of tumour promoter $(100 \mu \mathrm{l}$ croton oil). Tumors were examined weekly and the experiment lasted for 15 weeks. Results: MEMM and curcumin significantly $(\mathrm{p}<0.05)$ reduced the tumour burden, tumour incidence and tumour volume, which were further supported by the histopathological findings.

Conclusion: MEMM demonstrated chemoprevention possibly via its antioxidant and anti-inflammatory activities, and the action of flavonoids like quercitrin.
\end{abstract}

Key words: Melastomaceae; skin cancer; anti-carcinogenic activity

\section{Introduction}

Cancer is one of the major public health problem areas and remains a major cause of mortality and morbidity in developing as well as in developed countries (Arya, and Kumar, 2011). One of the commercial ways of providing treatments for cancer patients is chemotherapy - using antineoplastic drugs to kill rapid dividing cells. However, these drugs effectiveness have been overshadowed by its associated side effects, which include harm to the rapid dividing cells (i.e. bone marrow, digestive tract and hair follicles) that later lead to immunosuppression, mucositis and hair loss (Nouri, 2008).

Interestingly, the phyto-chemical constituents of some herbs and medicinal plants contain bioactive compounds that displayed potent anti-tumor or anti-carcinogenesis activity and are, therefore, important in the cancer preventive strategy in order to inhibit, delay or reverse carcinogenesis (Surh, 2002). One of the plants that are being studied in our laboratory is a small shrub belonging to the family Melastomaceae known as Melastoma malabathricum L. Smith. This medicinal plant has been scientifically reported to possess various pharmacological activities including the antioxidant, cytotoxic and, anti-inflammatory activities (Zakaria et al., 2011) that have been associated as parts of the mechanism of anti-carcinogenesis (Arya and Kumar, 2011). It is eminent that there is association between the mechanisms of oxidation inflammation, and cancer and the capability to hamper any of the mechanisms will definitely lead to the inhibition of the others. Nitric oxide (NO), for instance, is generated /liberated under the action of inflammatory stimuli such as the reactive oxygen species (ROS). Hence, inhibition of ROS results in decrease production of NO, which, in turn, triggered the antioxidant, anti-inflammatory, and anticancer processes (Robak and Gryglewski 1988; Middleton et al. 2000; Olszanecki et al. 2002). Interestingly, M. malabathricum has been reported to exert antioxidant and anti-inflammatory activities and, therefore, is believed to also possess anticancer activity. Moreover, the free radical scavenging effect is suggested to play important role through which this plant might exert its anticancer activity. However, since these association have not been proven scientifically, the present study was carried out to study the anti-carcinogenesis activity of methanol extract of M. malabathricum leaves (MEMM) using the 7,12-dimethylbenz( $\alpha$ )anthracene (DMBA)/crotton oil-induced mouse skin carcinogenesis model.

\section{Materials and Method \\ Plant leaves collection and preparation of methanol extract}

The leaves of M. malabathricum were collected around Serdang, Selangor, Malaysia between September and October, 2011 and a voucher specimen (SK 1986/11) was deposited at the herbarium of Institute of Bioscience (IBS), Universiti Putra Malaysia (UPM), Serdang, Selangor, Malaysia. The MEMM was prepared according to the method described in detail by Zakaria et al. (Zakaria et al., 2011). Basically, from $410 \mathrm{~g}$ of dried leaves soaked in methanol (Fischer Scienctific, UK) three times (1:20 (w/v); room temperature for $72 \mathrm{hr}$ ) yielded approximately $108.34 \mathrm{~g}$ of dried MEMM. The concentrated MEMM was further dried in an oven $\left(40^{\circ} \mathrm{C}\right)$ to eliminate excess methanol residue. Prior to use, the MEMM was dissolved in acetone (Mallinckrodt Chemicals, USA) to make up the concentrations of $30,100 \mathrm{and} 300 \mathrm{mg} / \mathrm{kg}$.

Forty eight (48) ICR strain female mice (6-7 weeks old; 20-28 g) were used in this study (Abel et al., 2009). The animals were kept in the Animal House, Faculty of Medicine and Health Sciences, UPM and cared according to the standard procedure described elsewhere 
(Zimmermann,1983). An ethical approval was received from the Animal Care and Use Committee of UPM (UPM/FPSK/PADS/BRUUH/00432). The animals were divided into six groups $(n=8)$ prior to the experimentation.

Three days before the application of DMBA, an area with $2 \mathrm{~cm} \times 2 \mathrm{~cm}$ of dorsal skin area of mice was shaved for application of chemicals. Briefly, in the initiation phase, each mouse in group II, III, IV, V and VI received a single dose of $100 \mu 1 / 100 \mu \mathrm{g}$ DMBA (SigmaAldrich Co, USA) on the dorsal shaved skin area and each animal was held for a few seconds to ensure the chemical distributed evenly on the shaved area before being released back into the cage. On the other hand, all mice in group I only received $100 \mu$ acetone.

Briefly, during the promotion phase, all mice in group I (vehicle control) received only $100 \mu$ l of acetone throughout promotion phase. On the other hand, the respective mice in group II (carcinogen control) and III (positive control) received $100 \mu 1$ of acetone or 10 $\mathrm{mg} / \mathrm{kg}$ curcumin (Sigma-Aldrich Co, USA) followed $30 \mathrm{~min}$ later by the application of $100 \mu \mathrm{l}$ of croton oil (Sigma-Aldrich Co, USA) throughout the promotion phase. Lastly, the respective mice in group IV, V and VI were treated with $100 \mu \mathrm{of} 30,100 \mathrm{and} 300 \mathrm{mg} / \mathrm{kg}$ MEMM, 30 minutes before the topical application of $100 \mu \mathrm{l}$ croton oil throughout the promotion phase. All treatments were applied twice weekly for fifteen weeks of promotion period.

Throughout the 15 weeks of experiment, the dorsal skin area was observed carefully for any papilloma growth as described in detail by (Abel et al., 2009). Briefly, several important parameters such as body weight, latency period of tumor formation, percentage of tumor incidence, tumor burden and tumor volume were also recorded weekly. The experiment was terminated on the $15^{\text {th }}$ week, and all animals were sacrificed by using diethyl ether and the dorsal skin was shaved and dissected out for histo-pathological analysis. The dissected skin tissues then underwent the standard Haematoxylin and Eosin $(\mathrm{H} \& \mathrm{E})$ staining procedure as described by Abel et al.

All data are presented as Mean \pm Standard Error of Mean (S.E.M.). The data were statistically analyzed using the one-way analysis of variance (ANOVA) followed by LSD multiple comparison test. Values with $\mathrm{p} \leq 0.05$ were considered as statistically significant.

\section{Results}

The body weight of mice receiving acetone, $10 \mathrm{mg} / \mathrm{kg}$ curcumin or, 30 and $100 \mathrm{mg} / \mathrm{kg} \mathrm{MEMM}$ increased gradually until week $15^{\text {th }}$ (data not shown). The initial and final body weight of mice in Group I to VI is shown in Table 1. Comparison between the initial (before promotion) and final body weight $\left(15^{\text {th }}\right.$ week after promotion $)$ demonstrated significant $(\mathrm{p}<0.05)$ increased in body weight in all groups except for the group receiving $300 \mathrm{mg} / \mathrm{kg}$ MEMM. This finding was supported by data for percentage of tumor incidence obtained at the end of experimental weeks ( $15^{\text {th }}$ week) wherein group II showed the highest tumor incidence (75.0\%) in comparison with Group I, III, IV, V and

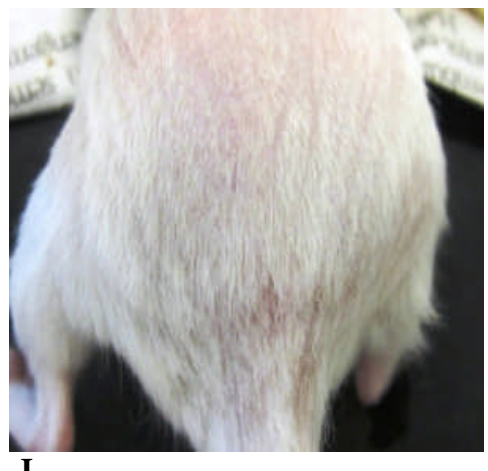

I

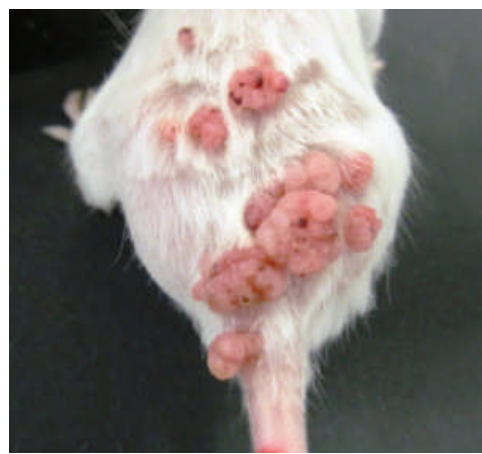

IV

V

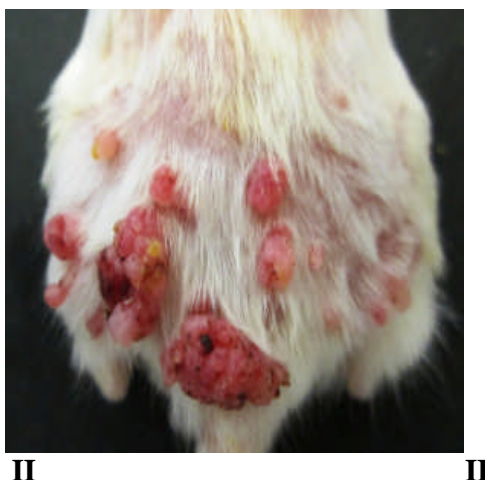

II

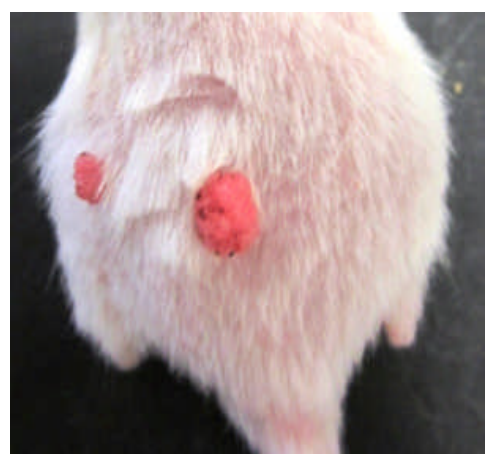

VI

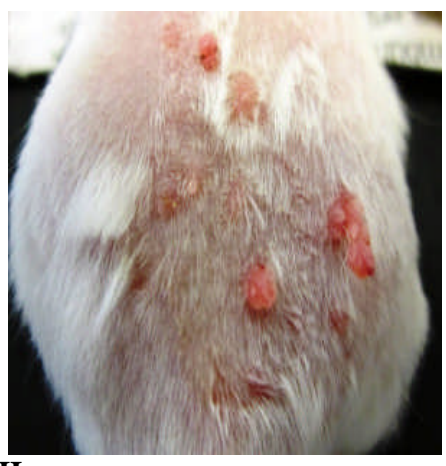

III

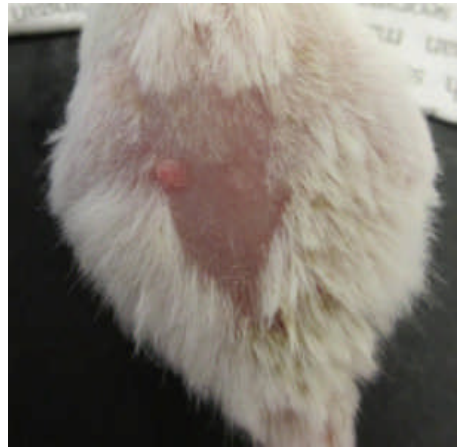

Figure 1. The gross appearance of the skin papilloma on the shaved dorsal skin of DMBA/croton oil-treated mice following the topical administration of MEMM or curcumin on week $15^{\text {th }}$. Representative photographs for each experimental group captured at the end of study. (I) Group I: vehicle control only applied with acetone; (II) Group II: carcinogen control only applied with $1 \%$ croton oil at the promotion stage and without any pre-treatment; (III) Group III: positive control treated with $10 \mathrm{mg} / \mathrm{kg}$ body weight curcumin; (IV) Group IV: treated with $30 \mathrm{mg} / \mathrm{kg}$ body weight MEDL; (V) Group V: treated with $100 \mathrm{mg} / \mathrm{kg}$ body weight MEDL, and; (VI) Group VI: treated with 300 $\mathrm{mg} / \mathrm{kg}$ body weight MEDL. 


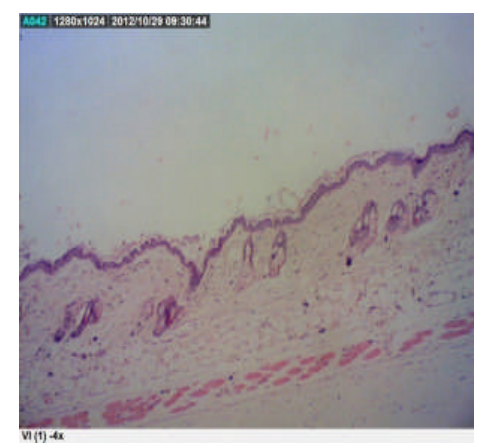

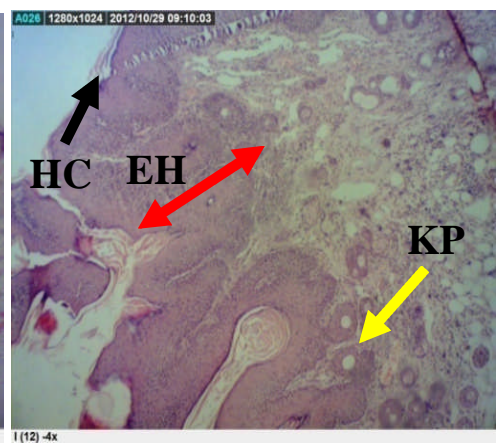

II

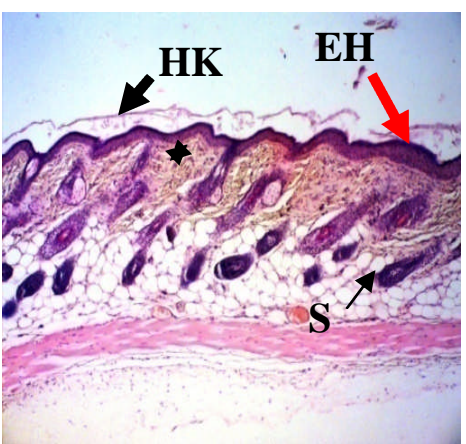

III

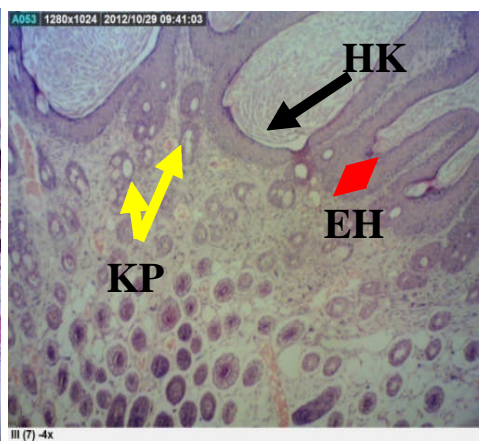

IV

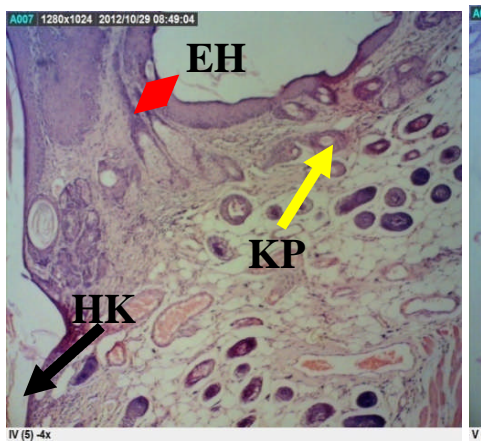

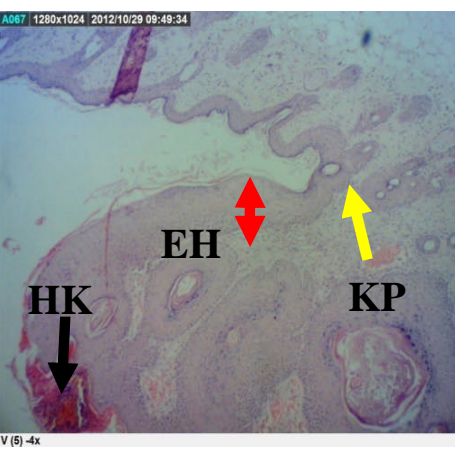

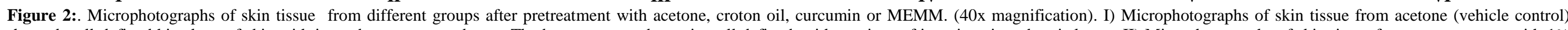

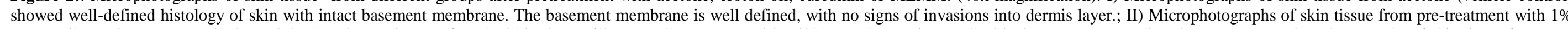

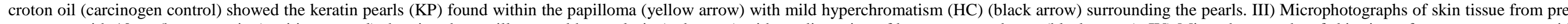

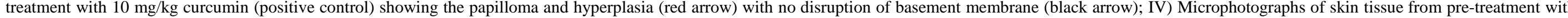

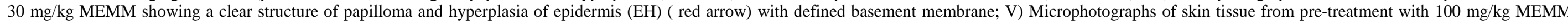

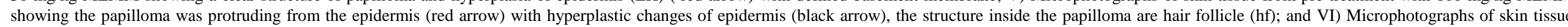

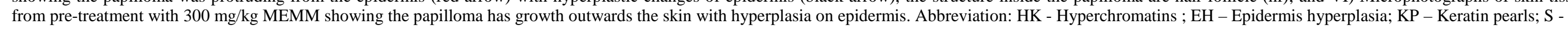


VI (tumor incidence range between 0-62.5\%) (Table. 1). There are significant $(\mathrm{p}<0.05)$ increased in tumor incidence with increase in period of exposure to carcinogenic agent, which were significantly $(\mathrm{p}<0.05)$ reduced following pre-treatment with curcumin or MEMM $(100$ and $300 \mathrm{mg} / \mathrm{kg}$ ). Groups receiving curcumin and MEMM exerted significant $(\mathrm{p}<0.05)$ reduction in tumor burden and tumor volume at the end of $15^{\text {th }}$ week with the latter occurred in a dose-dependent manner (Table 1). The tumor burden increased from Group I to Group VI followed by Group III, V, IV and II. The largest tumor volume was found in Group VI followed by Group V, IV, II and III. Group I has no tumor volume. As for the latency period of tumor formation, curcumin and MEMM $\left(30,100\right.$ and $300 \mathrm{mg} / \mathrm{kg}$ ) delayed the formation of tumor until week $10^{\text {th }}$, $8^{\text {th }}, 9^{\text {th }}$ and $14^{\text {th }}$, respectively in comparison to the negative control group (week $7^{\text {th }}$ ) (data not shown). The overall gross appearance of the shaved dorsal skin of a representative mouse from all the treatment groups on week 15 prior to dissection supported the ability of curcumin and MEMM to exert anti-carcinogenic activity (Figure 1) and supported by the microscopic examination (Figure 2).

\section{Discussion}

Results obtained from the present study confirmed the novel anti-carcinogenic activity of MEMM in DMBA/croton oil-induced mice. The DMBA initiates skin tumor formation through the generation ROS that are responsible for genetic materials damage (Das et al., 2010). Therefore, the chemoprevention activity of MEMM could be attributed to the extract's antioxidant activity, which, in turn, could be associated with the extract's phytochemical constituents (e.g. flavonoids, triterpenes, tannins and saponins) (Surh, 2002; Zakaria et al., 2011). MEMM has demonstrated high antioxidant and free radical scavenging potential when assessed by the DPPH radical scavenging and superoxide scavenging assays suggesting these effects direct or indirect contribution to the extract's observed anti-carcinogenic activity (Li et al. 2008). Compounds like flavonoids (Ferguson et al. 2004), saponins (Lemeshko et al. 2006), triterpenes (Kimura et al. 2002) and tannins (Ait Mbarek et al. 2007) have all been reported to possess antioxidant and anticancer activities and are, therefore, believed to act synergistically within the respective extract to cause the observed anti-carcinogenic activity.

In term of the mechanisms of anti-carcinogenesis that might be modulated by MEMM, several pathways could be suggested based on the flavonoids detected in MEMM. Flavonoids are important in the impediment of various chronic maladies involving oxidative stress and demonstrated antioxidant, anti-inflammatory and anticancer activities via the in vivo and in vitro models (Lee et al. 2003; Middleton et al. 2000; Robak and Gryglewski, 1988; Calixto et al. 2003; 2004). Moreover, flavonoids also regulated the expression of pro-inflammatory genes (i.e. nitric oxide synthase (NOS) and cyclooxygenase-2 (COX-2)) (Dawson and Snyder, 1994; Kim et al., 2004).

Interestingly, we have also detected quercitrin in the MEMM (Mamat et al., 2013), which have been earlier reported to exert in vitro anti-carcinogenic activity against mouse JB6 cells and antioxidant activities (Ding et al., 2010). Moreover, quercitrin down-regulates transactivation of AP-1 and NF- $\mathrm{BB}$ induced by UVB or TPA. Quercitrin was also shown to inhibit several biochemical pathways (i.e. ERKs, p38 kinase, and JNKs) related to cancer via the inhibition of MAPKs phosphorylation. In addition, quercitrin stimulated the activation of NFE2-related factor (Nrf2) and GST ARE-luciferase activity.

On the other hand, curcumin had been chosen as the positive control in comparison to the MEMM since curcumin contains antiinflammatory properties which lead to its effectiveness as a chemo-preventive agent (Sonavane et al., 2012). In conclusion, MEMM exhibited chemoprevention activity, which is attributed, partly, to its antioxidant activity and phyto-constituents, particularly, quercitrin.

Conflict of interest: The authors declare that there is no conflict of interest.

\section{Acknowledgement}

The authors thanked the Ministry of Science, Technology and Innovation (MOSTI), Malaysia for providing the Science Fund research grant (Ref. no.: 06-01-04-SF1127) and the University Putra Malaysia (UPM), Selangor, Malaysia for providing the Research University Grant Schemes 2012 (Ref. no.: 04-02-12-2019RU) to carry out the experiment. The authors also thanked the Faculty of Medicine and Health Sciences, UPM, Selangor, Malaysia for providing the facilities to carry out the experiments.

\section{References}

1. Abel EL, Angel JM, Kiguchi K, DiGiovanni J. Multi-stage chemical carcinogenesis in mouse skin: Fundamentals and applications. Nat Protoc 2009; 4: 1350-1362.

2. Ait Mbarek L, Ait Mouse H, Elabbadi N, Bensalah M, Gamouh A, Aboufatima R et al. Anti-tumor properties of blackseed (Nigella sativa L.) extracts. Braz J Med Biol Res 2007; 40: 839-847.

3. Arya P, Kumar M. Chemoprevention by Triticum Aestivum of mouse skin carcinogenesis induced by DMBA and croton oil Association with oxidative status. Asian Pacific J Cancer Prev 2011; 12: 143-148.

4. Calixto JB, Otuki MF, Santos ARS. Anti-inflammatory compounds of plant origin. Part I. Action on arachidonic acid pathway, nitric oxide and nuclear factor $\kappa-B$ (NFkB). Planta Med 2003; 69: 973-983.

5. Calixto JB, Campos MM, Otuki MF, Santos ARS. Anti-inflammatory compounds of plant origin. Part II. Modulation of proinflammatory cytokines, chemokines and adhesion molecules. Planta Med 2004; 70: 93-103.

6. Das I, Das S, Saha T. Saffron suppresses oxidative stress in DMBA-induced skin carcinoma: A histopathological study. Acta Histochem 2010; 12: 317-327.

7. Dawson TM, Snyder SH. Gases as biological messengers: Nitric oxide and carbon monoxide in the brain. J Neurosci 1994; 14: 51475159.

8. Ferguson PJ, Kurowska E, Freeman DJ, Chambers AF, Koropatnick DJ. A flavonoid fraction from cranberry extract inhibits proliferation of human tumor cell lines. J Nutr 2004; 134: 1529-1535.

9. Kim HP, Son KH, Chang HW, Kang SS. Anti-inflammatory plant flavonoids and cellular action mechanisms. J Pharmacol Sci 2004; 96 : 229-245.

10. Kimura Y, Taniguchi M, Baba K. Antitumor and antimetastatic effects on liver of triterpenoid fractions of Ganoderma lucidum: Mechanism of action and isolation of an active substance. Anticancer Res 2002; 22: 3309-3318.

11. Lee KW, Kim YJ, Lee HJ, Lee CY. Cocoa has more phenolic phytochemicals and a higher antioxidant capacity than teas and red wine. J Agric Food Chem 2003; 51: 7292-7295. 
http://dx.doi.org/10.4314/ajtcam.v11i4.11

12. Lemeshko VV, Haridas V, Quijano Perez JC, Gutterman JU. Avicins, natural anticancer saponins, permeabilize mitochondrial membranes. Arch Biochem Biophys 2006; 454: 114-122.

13. Li F, Wang F, Yu F, Fang Y, Xin Z, Yang F, Xu J, Zhao L, Hu Q. In vitro antioxidant and anticancer activities of ethanolic extract of selenium-enriched green tea. Food Chem 2008; 111: 165-170.

14. Mamat SS, Kamarolzaman MFF, Yahya F, Mahmood ND, Shahril MS, Jakius KF et al. Methanol extract of Melastoma malabathricum leaves exerted antioxidant and liver protective activity in rats. BMC Comp Alternat Med 2013; 13: 326.

15. Middleton Jr. E, Kandaswami C, Theoharides TC. The effects of plant flavonoids on mammalian cells: implications for inflammation, heart disease, and cancer. Pharmacol. Rev 2000; 52: 673-751.

16. Nouri K. Skin Cancer. 2nd ed. New York : McGraw-Hill; 2008; pp. 1-17.

17. Robak J, Gryglewski RJ. Flavonoids are scavengers of superoxide anions. Biochem Pharmacol 1988; 37: 837-841.

18. Sonavane K, Phillips J, Ekshyyan O, Moore-Medlin T, Gill JR, Rong X et al. Topical curcumin-based cream is equivalent to dietary curcumin in a skin cancer model. J Skin Cancer 2012; 2012, Article ID147863; doi: 10.1155/2012/147863.

19. Surh YJ. Anti-tumor promoting potential of selected spice ingredients with antioxidative and anti-inflammatory activities: A short review. Food Chem Toxicol 2002; 40: 1091-1097.

20. Zakaria ZA, Rofiee MS, Mohamed AM, Teh LK, Salleh MZ. In vitro antiproliferative and antioxidant activities and total phenolic contents of the extracts of Melastoma malabathricum leaves. J Acupunct Meridian Stud, 4: 248-256.

21. Zimmermann M. Ethical guidelines for investigations of experimental pain in conscious animals. Pain 1983; 6: 109-110. 